$\$$ sciendo

\title{
Necessity and Color Incompatibility
}

\author{
Brian Kierland \\ Boise State University \\ Disputatio Vol. 4, No. 31 \\ November 2011
}

DOI: 10.2478/disp-2011-0010

ISSN: 0873-626X 


\title{
Necessity and Color Incompatibility
}

\author{
Brian Kierland \\ Boise State University
}

\begin{abstract}
A traditional view is that all necessary truths are analytic. A frequent objection is that certain claims of color incompatibility - e.g., 'Nothing is both red and green all over' - are necessarily true but not analytic. I argue that this objection to the traditional view fails because such color incompatibility claims are either analytic or contingent.
\end{abstract}

\section{Keywords}

Necessity, analyticity, color, color incompatibility

A traditional view is that all necessary truths are analytic; this view was popular in part because it promised to reduce necessity to analyticity (see, e.g., Ayer 1952). A frequent objection (one independent of and predating the critique in Kripke 1980) is that certain claims of color incompatibility are necessarily true but not analytic (see, e.g., Pap 1949). For example, it is claimed that 'Nothing is both red and green all over' is necessarily true but not analytic. Although I have no interest in defending the traditional view, I shall argue that this particular objection fails. In what follows, I will simply assume there is a coherent notion of analyticity of the sort commonly employed by philosophers, something along the lines of 'built into the very meaning of'. The traditional view might be false because this assumption is incorrect, but that is a different objection.

My position is that 'Nothing is both red and green all over' and similar color incompatibility claims are either analytic or contingent. To see this, take two objects, one red all over and the other green all over, and hold them in front of you. In particular, hold them side-by-side but close together six to eight inches from your face, so that one object is in front of your left eye and the other in front of your right eye. Now look straight ahead but focus well beyond the two objects. Your visual experience will then include two images of each of these objects; this sort of double vision is a normal condition known as physiological diplopia. In the center of your visual field, one image of one of the objects will overlap one image of the

Disputatio, Vol. IV, No. 31, November 2011

Received on 17 March 2011 
other object. So long as you do not let the image from one eye be dominant, you will have an experience in that portion of your visual field which it would be natural to describe as "both red and green". This experiment establishes the possibility of a certain kind of experience, call it a greddish experience. (The experiment requires that one be sighted in both eyes. Those who are not might just have to take the word of those who are.)

As things actually are, one has greddish experiences only when conducting experiments of the sort just described. But it is surely possible to have greddish experiences in different circumstances; e.g., it is surely possible for different combinations of environmental conditions and eye focusing to cause the brain state which actually is identical to or constitutes or underlies or causes the having of a greddish experience. Consequently, a certain kind of object is also possible: a single object which, when visually focused upon, causes one to have a greddish experience in the portion of one's visual field representing or corresponding to the object. Just as we attribute colors to the objects we actually encounter, were we to encounter such an object, we would attribute to it a certain heretofore unknown color or color-like surface property; call this property gred. I assume that, in such circumstances, we would be no more mistaken in taking certain objects to be gred than we would in taking various more ordinary objects to be green.

There is a certain obvious qualitative surface resemblance between green objects and gred objects. To capture this, let us say that both are green*. (Similarly for red objects and gred objects, a resemblance we can capture by saying that both are red*.) Now we face a dilemma. Horn one: it is built into the very meaning of 'red' that red objects are not green*. But since, by definition of 'green*', all green objects are green*, it follows that 'Nothing is both red and green all over' is analytic. Horn two: it is not built into the very meaning of 'red' that red objects are not green*. In that case (so long as the parallel holds for 'green' and red*), 'Nothing is both red and green all over' is contingent, since then it is possible for an object to be both red and green all over; the possible object described in the previous paragraph then fits the bill. Conclusion: 'Nothing is both red and green all over' is either analytic or contingent.

Brian Kierland

Department of Philosophy Boise State University 1910 University Drive

Boise, Idaho 83725,USA briankierland@boisestate.edu 


\section{References}

Ayer, Alfred Jules. 1952. Language, Truth and Logic. New York: Dover.

Kripke, Saul. 1980. Naming and Necessity. Cambridge, MA: Harvard University Press.

Pap, Arthur. 1949. Are All Necessary Propositions Analytic? The Philosophical Review 58: 299-320. 